\title{
Effects of Group Behavior in The Predatory Raid on Damselfish Nests By The False Cleanerfish Aspidontus Taeniatus
}

\author{
Hajime Sato ( $\square$ hsato98@outlook.jp )
}

Hiroshima University

\section{Yoichi Sakai}

Hiroshima University

\section{Tetsuo Kuwamura}

Chukyo University

\section{Research Article}

Keywords: Aspidontus taeniatus, egg-eating, Pomacentridae, Balistidae

Posted Date: February 16th, 2021

DOl: https://doi.org/10.21203/rs.3.rs-198194/v1

License: (c) (i) This work is licensed under a Creative Commons Attribution 4.0 International License. Read Full License

Version of Record: A version of this preprint was published at Ethology on October 22nd, 2021. See the published version at https://doi.org/10.1111/eth.13242. 


\section{Abstract}

The benefits of group behavior have been reported in a variety of animals. The false cleanerfish Aspidontus taeniatus, which resembles the bluestreak cleaner wrasse Labroides dimidiatus, is the bestknown example of mimicry in vertebrates. This mimicry system has been viewed as an aggressive mimicry to bite fish fins. However, recent field studies have reported that large individuals of the false cleanerfish form groups and jointly raid fish nests to eat eggs that are guarded by their parents. Since the cleaner wrasse does not form such groups or specialize in egg-eating, the feeding groups of the false cleanerfish is assumed to reduce the effectiveness of mimicry. Here, we conducted field observations to clarify the functions of group behavior in egg-eating in the false cleanerfish. The false cleanerfish formed groups of 2-12 individuals when they raided breeding nests of 13 damselfish (Pomacentridae) and one triggerfish (Balistidae). The results showed that the group behavior has two effects: a dilution effect, which reduces the risk of being attacked by egg-guarding fish, and an increase in foraging efficiency. We conclude that the false cleanerfish need to form cooperative foraging groups during egg-eating because the egg-guarding parents could see through the mimicry.

\section{Introduction}

Group behavior, which often increases the fitness of an individual, has evolved in a wide variety of animals ${ }^{[1]}$. The adaptive significance of group behavior is categorized based on the benefits gained. For example, strategies against predators ${ }^{[2-7]}$, increased foraging efficiency ${ }^{[8-10]}$, breeding leks ${ }^{[11]}$, protection from desiccation and heat loss ${ }^{[12,13]}$, and reduced cost of transport ${ }^{[14]}$ have been reported. Among them, the first two benefits are important survival strategies in predator-prey interactions. The simplest and best-known function of the anti-predator strategy is the dilution effect, which reduces the probability that an individual will be preyed upon ${ }^{[2]}$. Assuming that attacks from predators do not increase proportionally with group size ( $\mathrm{N}$ individuals) and that attacks are not biased against specific individuals, the probability of an attack on each individual decreases inversely with group size to $1 / \mathrm{N}^{[1]}$. Prey animals, constantly in danger of predation, reduce their chances of being attacked, and increase their survival rate by forming larger groups ${ }^{[2-4]}$. On the other hand, a famous example of group behavior, known as tactics on the part of predators, is the group hunting of carnivorous animals to increase foraging efficiency ${ }^{[8,9]}$. For example, lions increase their hunting success by cooperating with other individuals of their pride to attack large buffaloes, which they cannot capture solitarily.

Dilution effects and increased foraging efficiency have also been reported in fish. The experimental results of the dilution effect have been proven by the reduction in the frequency of attacks from the white perch, Morone americana, by schools of the banded killifish, Fundulus diaphanus ${ }^{[15]}$. For three-spined sticklebacks, Gasterosteus aculeatus, experimental evidence suggests that individuals prefer larger schools to smaller ones because larger schools are expected to be more effective in reducing predation [16]. Thus, the dilution effect is commonly observed in fish. In addition, increased foraging efficiency due to group foraging has been observed in some fish species. The jack, Caranx ignobilis, which is a 
piscivore, panics its prey, the Hawaiian anchovy, Stolephorus purpureus, by attacking simultaneously in groups, thereby increasing its hunting success ${ }^{[17]}$. The sailfish, Istiophorus platypterus, also forms large groups and improves foraging efficiency through proto-cooperative group hunting ${ }^{[18,19]}$. A surprising example of hunting tactics is the interspecific communicative and coordinated hunting between the roving grouper, Plectropomus pessuliferus, and the giant moray, Gymnothorax javanicus ${ }^{[20-22]}$. The roving grouper and giant moray increase their hunting success by combining their complementary hunting skills.

The false cleanerfish Aspidontus taeniatus (Blenniidae), which inhabits coral reefs in the Indo-West Pacific, closely resembles the bluestreak cleaner wrasse, Labroides dimidiatus (Labridae), a well-known obligate cleaner. Cleaner fish mimicry is considered as the most elaborate mimicry in vertebrates ${ }^{[23]}$. Two functions are considered in this mimicry system of the false cleanerfish: success in fin-biting (aggressive mimicry or Peckhamian mimicry), as the false cleanerfish can bite off the pieces of the caudal fin of a deceived fish, and protection from predation (protective mimicry or Batesian mimicry), as the bluestreak cleaner wrasse is not easily preyed through cleaning symbiosis ${ }^{[23]}$. Wickler ${ }^{[23]}$ emphasized the former finbiting behavior from aquarium observations. However, recent field studies have shown that false cleanerfish also feed on benthic animals such as tentacles of tubeworms, Spirobranchus giganteus, and mantles of boring clams, Tridacna crocea ${ }^{[24-27]}$, and that fin-biting is a critically important alternative foraging tactic in small individuals when they settle into localities with poor benthic foods ${ }^{[25]}$. Moreover, large $A$. taeniatus form groups and raid damselfish (Pomacentridae) nests for eating demersal eggs, which are guarded by parental fish ${ }^{[24,26,27]}$. The bluestreak cleaner wrasse, the model species of the mimicry, spends a lot of time in pairs, but neither form groups ${ }^{[28,29]}$, nor eat damselfish eggs ${ }^{[30]}$. In general, the effectiveness of mimicry is enhanced when the number of mimics is sufficiently small compared with that of the model species ${ }^{[23]}$. The group behavior of the false cleanerfish may reduce the effect of mimicry. To understand the evolution of mimicry in this system, it is necessary to clarify the factors that have led to the development of group behavior that conflicts with mimicry.

In this study, we attempted to test the following two hypotheses by observing the behavior in the field to suggest that group behavior has evolved to feed on damselfish eggs and that its benefits are higher than the effects of mimicry. We predicted that the group behavior of the false cleanerfish would have two functions: a dilution effect (Hypothesis 1 ) to reduce the risk of injury due to attacks from parental damselfish, and an increased foraging efficiency (Hypothesis 2) to increase the success rate of nest invasion. Although the dilution effect in Hypothesis 1 is strictly different from the anti-predator strategy described at the beginning of the introduction ${ }^{[1,2]}$, a similar mechanism would exist in predators who receive counterattacks.

\section{Methods}

\section{Study site and species}


Field observations were conducted in a coral reef protected area of approximately $100 \mathrm{~m} \times 350 \mathrm{~m}$ $\left(127^{\circ} 52^{\prime} \mathrm{E}, 26^{\circ} 38^{\prime} \mathrm{N}\right)$, in front of the Tropical Biosphere Research Center, University of the Ryukyus, Sesoko Island, Okinawa, Japan, between April and October 2019. The study site was a fringing reef with a sandy bottom off the reef edge at a depth of $5 \mathrm{~m}$ (during high tide). The reef was species-rich with benthic animals (tubeworms, 4.8 individuals per $5 \mathrm{~m}^{2}$; boring clams, 14.5 individuals per $5 \mathrm{~m}^{2}{ }^{[25]}$ ), small fishes as targets for fin-biting, and fish eggs, which are seasonal resources. All the damselfish and triggerfish species observed in this study spawned during the warm season from April to October (Table 1).

All individuals of the false cleanerfish were identified by tagging. Fish were captured using a screen net and a hand net, immediately brought back to the laboratory, anesthetized with clove oil, measured for total length, sexed by external genitalia, photographed on both sides of the body, and injected subcutaneously with fluorescent elastomer tag (Northwest Marine Technology, Shaw Island, USA). As soon as the marking was completed, they were recovered with fresh seawater and returned to the captured point.

For testing the two hypotheses, we examined the raiding behavior of the false cleanerfish against the scissors-tail sergeant, $A$. sexfasciatus, which was the most frequently observed in this study (see Table 1). The scissors-tail sergeant is one of the damselfishes commonly observed in the study reef ${ }^{[39]}$. Parental male fish care eggs laid on rock surfaces until they hatch ${ }^{[40]}$, and on Sesoko Island, eggguarding males formed breeding colonies. During egg-guarding, they showed defensive behavior chasing all the fish that approached their nests. We used 19 cases of raiding behavior against the scissors-tail sergeant for which video data were obtained (recording time: median $52 \mathrm{~s}$, range 18-201 s) to quantitatively test our hypothesis.

\section{Behavioral observation}

All field work was conducted by snorkeling. Between 07:00 and 18:00, a randomly chosen individual in the study area was tracked from behind for at least $30 \mathrm{~min}$, and the following items were visually recorded on the waterproof datasheet: time spent swimming with other individuals per $30 \mathrm{~min}$ as a group activity; group size; the number of feeding occasions (bites on fish-fins, tubeworms, and boring clams); the number of raids on fish nests and invasion time; and the number of attacks from other fishes. The target species for egg-eating were photographed with an underwater camera (TG5 Tough; Olympus, Tokyo, Japan) to identify the species.

As for the nest-raiding behavior toward the scissors-tail sergeant, the entire bouts were captured by videos. Based on the video data, we counted the number of times the false cleanerfish were chased (as damselfish attacks), jumped into the nest of the scissors-tail sergeant, and whether it succeeded or not. We defined one "nest-raiding" event as the time from when they started targeting the eggs until they moved away from the nest, regardless of the success or failure. In the case of no eggs in the nest (3/19 bouts), the false cleanerfish had mistakenly raided the nest; however, the scissors-tail sergeant always 
defended their nest; therefore, we treated them as nest-raiding data. The false cleanerfish were sometimes attacked by other egg-guarding males that were not the target damselfish because the males always formed colonies (13/19 bouts). Since these attacks can also be assumed as a cost of egg-eating, they were included in the data analysis.

\section{Statistical analysis}

Non-parametric tests for statistical analyses were used, and all data characteristics were presented as medians and ranges. All the correlation analyses were performed using Spearman's rank correlation coefficient test. As group activities of individuals, we calculated the percentage of the swimming time spent with other individuals in 30 min tracking, to examine the relationship between group activity and total length. The frequency of damselfish attacks per $10 \mathrm{~s}$ was calculated (10 * [total number of attacks/nest-raiding time]), and the correlation with group size was analyzed from the video data. The success rate of nest invasion of the false cleanerfish was calculated (100* [success trials/total trials]), and the correlation with group size was analyzed from the video data. All analyses were performed using the free statistical software, R ver. 4.01 (R Development Core Team, 2020) ${ }^{[41]}$.

\section{Ethical statement}

All procedures performed in this study followed the Guidelines for the Proper Conduct of Animal Experiments and related activities laid down by the Hiroshima University Animal Research Committee (No. 020A170410 certified on April 10th, 2017), the ASAB/ABS Guidelines for the Use of Animals in Research (Guidelines for the Treatment of Animals in Behavioral Research and Teaching; https://doi.org/10.1016/j.anbehav.2019.11.002), the Guidelines for the Use of Fishes in Research by the Ichthyological Society of Japan (http://www.fish-isj.jp/english/guidelines.html), and the Guideline for Ethological Studies by the Japan Ethological Society(http://www.ethology.jp/guideline.pdf).

\section{Results}

The false cleanerfish formed groups of 2-12 individuals before raiding the damselfish nests. One randomly selected individual was tracked for $30 \mathrm{~min}$ (total length of observed individuals: median 90 $\mathrm{mm}$, range 55-118 mm, $N=55$ individuals). During tracking, the false cleanerfish repeatedly met and separated from other individuals, and not only ate fish eggs (Fig. 1a; Electric Supplementary Information Video S1), but also bit the tentacles of tubeworms, the mantles of boring clams, and fish fins. There was a significant positive correlation between the group activity (frequency of group behavior per swimming time of 30 min tracking: median $96.7 \%$, range $0-100 \%, N=55$ ) and the total length of the false cleanerfish (Spearman's rank correlation, $r_{s}=0.319, N=55, P=0.018$; Fig. 2).

Fish nest-raiding by the false cleanerfish was observed 128 times, and the target species were 13 damselfish and one triggerfish (Balistidae) (Table 1). Fish eggs were laid on visible surfaces (open-type nests) such as dead corals, rocky substrate, sand, filamentous algae (Polysiphonia spp.), and soft corals (Lobophytum spp.), or in invisible deep places (closed-type nest) such as crevices of massive corals 
(Porites spp.). The eggs were guarded by the male parent of the damselfish and by the female parent of the triggerfish. In a single raid, the false cleanerfish was able to eat eggs for 9.5 seconds (median, range 0-87 sec., $N=106$ bouts), and when successful, they ate enough eggs to fill their stomach (Fig. 1b).

The false cleanerfish could succeed in raiding continuously, but sometimes it failed because the parental fish blocked it. However, during the raid, whether they succeeded or failed, the false cleanerfish were always attacked by the parental fish by darting, flapping, and biting, and the attacks were fierce enough to cause external injuries (Fig. 1c). The egg-guarding fish always showed aggressive attacks as chasing away all fish approaching their nests, especially the false cleanerfish. They recognized $A$. taeniatus as a potential egg predator and preemptively attacked it from a distance of approximately 1-2 m, even if it did not try to raid the nest. The false cleanerfish were attacked by egg-guarding fish approximately 2.0 times per 30 min (median, range $0-19$ times, $N=55$ ). In addition, five species of damselfishes (Abudefduf sexfasciatus, Plectroglyphidodon lacrymatus, Stegastes obreptus, Stegastes nigricans, and Dascyllus trimaculatus) produced clear threatening sounds during attack. These preemptive attacks or threatening sounds were not shown against the bluestreak cleaner wrasse.

The scissors-tail sergeant, $A$. sexfasciatus, was the most targeted damselfish species for egg-eating by the false cleanerfish (32\%, 41/128 trials; Table 1). The group size of the false cleanerfish at the time of nest-raiding was approximately four individuals (median, range 1-9 individuals, $N=19$ ), and the scissors-tail sergeant attacked the group on 15 occasions (median, range $3-37$ occasions, $N=19$ ). There was no significant correlation between the group size of the false cleanerfish and the total number of attacks by the scissors-tail sergeant (Spearman's rank correlation, $r_{s}=0.323, N=19, P=0.177$ ). Regarding Hypothesis 1 , the frequency of attacks (10*[total number of attacks/nest-raiding time]/group size) received by one individual from the scissors-tail sergeant in $10 \mathrm{~s}$ decreased significantly with group size (Spearman's rank correlation, $r_{s}=-0.806, N=19, P=0.00003$; Fig. 3 ). Regarding Hypothesis 2 , the success rate $(100 *$ [success trials/total trials]) of nest invasion of the false cleanerfish increased significantly with group size (Spearman's rank correlation, $r_{s}=0.554, N=19, P=0.013$; Fig. 4). In a single nest-raiding, an individual of the false cleanerfish made approximately 3.0 attempts to invade the nest (median, range $0.5-9.5$ trials, $N=19$ ). There was no significant correlation between the number of trials and group size (Spearman's rank correlation, $r_{s}=-0.204, N=19, P=0.401$ ).

\section{Discussion}

As a foraging strategy for the false cleanerfish, $A$. taeniatus, there is a trade-off between the group behavior and the effect of mimicry. To date, there have been no studies that have examined examples of mimetic species forming foraging groups and their adaptive significance based on quantitative data. The results of this study, based on the observations of egg-eating in the field, showed that group activity increased at 70-80 $\mathrm{mm}$ in total length and that group behavior had two effects: dilution effect (Hypothesis 1, Fig. 3) and increased foraging efficiency (Hypothesis 2, Fig. 4). This suggests that even 
well-designed mimics do not always behave in a way that maximizes the functions of mimicry, and that other strategies, such as group behavior, can naturally evolve if the benefits change with growth ${ }^{24,25]}$.

Fish eggs are an ideal food resource because they have a much higher nutritional value in comparison with fish fins and benthic animals ${ }^{[31,32]}$, and on successful invasion of a nest, the false cleanerfish can feed enough to fill their stomachs (Fig. 1b). However, Fujisawa et al. ${ }^{[24,25]}$ suggested that fin-biting is an important foraging tactic in small individuals when benthic foods are scarce. One of the factors that may cause smaller individuals to choose fin-biting, rather than egg-eating, is the differential risk of injury from attacks by parental fishes. Both fin-biting and egg-eating are risk-taking behaviors: in the case of finbiting, the false cleanerfish approaches a small target fish from its rear to bite its caudal fin and will sometimes be chased by the target fish after biting ${ }^{[24,25]}$, but attacks by parental fish are much more aggressive during egg-eating (Fig. 1c). For small $A$. taeniatus individuals who do not have strong escaping capabilities, the cost of injury would be a constraint on egg-eating. Therefore, it is assumed that smaller individuals choose fin-biting instead of egg-eating. The fact that smaller individuals, less than 70 $\mathrm{mm}$ in total length, were less likely to form a group may be due to the period when they need to increase the effectiveness of aggressive mimicry (fin-biting).

In larger individuals of $A$. taeniatus, the evolution of group behavior, which may reduce the effectiveness of mimicry, may be due to an arms race with the learning ability of parental damselfish. In the early stages of the evolution of egg-eating, the damselfish may not have been able to see through the mimicry; however, they presently quickly recognize the false cleanerfish as an egg predator. Damselfish have been known to have a high level of species and individual recognition based on visual cues ${ }^{[33-35]}$. For example, Goiran \& Shine ${ }^{[35]}$ reported that damselfish could distinguish between egg predatory species of sea snakes, Emydocephalus annulatus, and four other species, Aipysurus duboisii, A. laevis, Hydrophis major, and Laticauda saintgironsi that do not eat eggs, and selectively attacked $E$. annulatus. Furthermore, the generalist piscivore and non-egg predator, $A$. duboisii, with a dark body color type similar to that of $E$. annulatus (egg predator), was attacked more in comparison with the pale type, suggesting that damselfish visually distinguish egg predators from non-egg predators. The results of our study support the idea that damselfish can visually recognize if a species is a threat for their eggs and can differentiate two species with elaborate morphological resemblance. The group behavior in the false cleanerfish may have evolved because the parental damselfish could recognize its mimicry during its eggeating and began to attack it. Large $A$. taeniatus do not change their mimetic coloration or pattern, even though they become less dependent on aggressive mimicry. Recently, a non-mimic color variant of the false cleanerfish was found off Sesoko Island, Japan, but it was a small individual, not a large one ${ }^{[36]}$. The reasons for the maintenance of the mimic color in larger individuals remain obscure.

It is a widely known strategy that coral reef fish form shoals or groups to access protected resources [37, ${ }^{38]}$. Our study examined the effects of group behavior in raiding the nests of the scissors-tail sergeant, and a similar survey should be conducted on other damselfish or triggerfish as egg-eating targets. There may be other functions of the group behavior. For example, group behavior may improve the detection of 
fish nests distributed in patches on coral reefs. To increase benefits and reduce the costs of group behavior, they may develop a role specialization such as individuals who have learned the location of the nests may lead other individuals who may not be aware of the nest sites and follow the leader. Future research will need to carefully focus not only on the simple functions of group behavior, but also on the roles of the individuals that comprise groups.

\section{Declarations}

\section{Acknowledgements}

We would like to thank the staff of the Sesoko Station, Tropical Biosphere Research Center at the University of the Ryukyus for supporting our field research, Dr. Jun-ya Shibata for his advice on statistical analysis, and Editage (www.editage.com) for English language editing. This work was supported by JSPS KAKENHI Grant Number 19 K06845 to T. Kuwamura.

\section{Author contributions}

Field research, data analysis, and manuscript writing were conducted by H.S. under the guidance of Y.S. and T.K. All authors have edited and approved the manuscript.

\section{Competing interests}

The authors declare no competing interests.

\section{Data availability}

The data that support the findings of this study are available from the corresponding author, H.S., upon reasonable request.

\section{Electronic Supplementary Information}

Video S1. Egg-eating behavior of the false cleanerfish, Aspidontus taeniatus, in a group. The target species was the scissors-tail sergeant, Abudefduf sexfasciatus. This video was taken on a reef of Sesoko Island by Hajime Sato.

\section{References}

1. Krause, J. \& Ruxton, G. D. Living in groups (Oxford University Press, 2002)

2. Foster, W. A. \& Treherne, J. E. Evidence for the dilution effect in the selfish herd from fish predation on a marine insect. Nature 293, 466-467 (1981). 10.1038/293466a0

3. Roberts, G. Why individual vigilance declines as group size increases. Anim. Behav. 51, 1077-1086 (1996). 10.1006/anbe.1996.0109 
4. Schradin, C. Confusion effect in a reptilian and a primate predator. Ethology 106, 691-700 (2000). 10.1046/j.1439-0310.2000.00582.x

5. Bertram, B. C. R. Social factors influencing reproduction in wild lions. J. Zool. 177, 463-482 (1975). 10.1111/j.1469-7998.1975.tb02246.x

6. Duncan, P. \& Vigne, N. The effect of group size in horses on the rate of attacks by blood-sucking flies. Anim. Behav. 27, 623-625 (1979). 10.1016/0003-3472(79)90201-X

7. Sweeney, B. W. \& Vannote, R. L. Population synchrony in mayflies: a predator satiation hypothesis. Evolution 36, 810-821 (1982). 10.1111/j.1558-5646.1982.tb05447.x, Pubmed:28568232

8. Kruuk, H. The Spotted Hyena: a study of predation and social behavior (University of Chicago Press, 1972)

9. Stander, P. E. Cooperative hunting in lions: the role of the individual. Behav. Ecol. Sociobiol. 29, 445454 (1992). 10.1007/BF00170175

10. Ward, P. \& Zahavi, A. The importance of certain assemblages of birds as "information-centres" for food-finding. Ibis 115, 517-534 (1973). 10.1111/j.1474-919X.1973.tb01990.x

11. Bradbury, J., Gibson, R. \& Tsai, I. M. Hotspots and the dispersion of leks. Anim. Behav. 34, 16941709 (1986). 10.1016/S0003-3472(86)80257-3

12. Clark, B. R. \& Faeth, S. H. The evolution of egg clustering in butterflies: a test of the egg desiccation hypothesis. Evol. Ecol. 12, 543-552 (1998). 10.1023/A:1006504725592

13. Andrews, R. V. \& Belknap, R. W. Bioenergetic benefits of huddling by deer mice (Peromyscus maniculatus). Comp. Biochem. Physiol. A 85, 775-778 (1986). 10.1016/0300-9629(86)90294-x, Pubmed:2879682

14. Bill, R. G. \& Herrnkind, W. F. Drag reduction by formation movement in spiny lobsters. Science 193, 1146-1148 (1976). 10.1126/science.193.4258.1146, Pubmed:17792754

15. Morgan, M. J. \& Godin, J. J. Antipredator benefits of schooling behaviour in a cyprinodontid fish, the banded killifish (Fundulus diaphanus). Z. Tierpsychol. 70, 236-246 (1985). 10.1111/j.14390310.1985.tb00515.x

16. Frommen, J. G., Hiermes, M. \& Bakker, T. C. M. Disentangling the effects of group size and density on shoaling decisions of three-spined sticklebacks (Gasterosteus aculeatus). Behav. Ecol. Sociobiol. 63, 1141-1148 (2009). 10.1007/s00265-009-0767-9

17. Major, P. F. Predator-prey interactions in two schooling fishes, Caranx ignobilis and Stolephorus purpureus. Anim. Behav. 26, 760-777 (1978). 10.1016/0003-3472(78)90142-2

18. Herbert-Read, J. E. et al. Proto-cooperation: group hunting sailfish improve hunting success by alternating attacks on grouping prey. Proc. R. Soc. B 283, 1842 (2016). 10.1098/rspb.2016.1671, Pubmed:27807269

19. Kurvers, R. H. J. M. et al. The evolution of lateralization in group hunting sailfish. Curr. Biol. 27, 521526 (2017). 10.1016/j.cub.2016.12.044, Pubmed:28190733 
20. Bshary, R., Hohner, A., Ait-el-Djoudi, K. \& Fricke, H. Interspecific communicative and coordinated hunting between groupers and giant moray eels in the Red Sea. PLOS Biol. 4, e431 (2006). 10.1371/journal.pbio.0040431, Pubmed:17147471

21. Vail, A. L., Manica, A. \& Bshary, R. Referential gestures in fish collaborative hunting. Nat. Commun. 4, 1765 (2013). 10.1038/ncomms2781, Pubmed:23612306

22. Vail, A. L., Manica, A. \& Bshary, R. Fish choose appropriately when and with whom to collaborate. Curr. Biol. 24, R791-R793 (2014). 10.1016/j.cub.2014.07.033, Pubmed:25202866

23. Wickler, W. Mimicry in plants and animals (McGraw-Hill, 1968)

24. Fujisawa, M., Sakai, Y. \& Kuwamura, T. Aggressive mimicry of the cleaner wrasse by Aspidontus taeniatus functions mainly for small blennies. Ethology 124, 432-439 (2018). 10.1111/eth.12743

25. Fujisawa, M., Sakai, Y. \& Kuwamura, T. The false cleanerfish relies on aggressive mimicry to bite fish fins when benthic foods are scarce in their local habitat. Sci. Rep. 10, 8652 (2020). 10.1038/s41598020-65304-6, Pubmed:32457505

26. Kuwamura, T. Reexamination on the aggressive mimicry of the cleaner wrasse Labroides dimidiatus by the blenny Aspidontus taeniatus (Pisces; Perciformes). J. Ethol. 1, 22-33 (1983).

10.1007/BF02347828

27. Cheney, K. L., Grutter, A. S. \& Bshary, R. Geographical variation in the benefits obtained by a coral reef fish mimic. Anim. Behav. 88, 85-90 (2014). 10.1016/j.anbehav.2013.11.006

28. Potts, G. W. The ethology of Labroides dimidiatus (cuv. \& val.) (Labridae, Pisces) on Aldabra. Anim. Behav. 21, 250-291 (1973). 10.1016/S0003-3472(73)80068-5

29. Kuwamura, T. Social Structure of the protogynous fish Labroides dimidiatus. Publ. SMBL 29, 117177 (1984). 10.5134/176083

30. Grutter, A. S. \& Bshary, R. Cleaner wrasse prefer client mucus: support for partner control mechanisms in cleaning interactions. Proc. R. Soc. B 270, 5242-5244 (2003). $10.1098 / \mathrm{rsbl} .2003 .0077$

31. Arnal, C., Côté, I. M. \& Mornand, S. Why clean and be cleaned? The importance of client ectoparasites and mucus in a marine cleaning symbiosis. Behav. Ecol. Sociobiol. 51, 1-7 (2001). $10.1007 / \mathrm{s} 002650100407$

32. Rønnestad, I., Thorsen, A. \& Finn, R. N. Fish larval nutrition: a review of recent advances in the role of amino acids. Aquaculture 177, 201-216 (1999). 10.1016/S0044-8486(99)00082-4

33. Siebeck, U. E. Communication in coral reef fish: the role of ultraviolet colour patterns in damselfish territorial behaviour. Anim. Behav. 68, 273-282 (2004). 10.1016/j.anbehav.2003.11.010

34. Karplus, I., Katzenstein, R. \& Goren, M. Predator recognition and social facilitation of predator avoidance in coral reef fish Dascyllus marginatus juveniles. Mar. Ecol. Prog. Ser. 319, 215-223 (2006). 10.3354/meps319215

35. Goiran, C. \& Shine, R. The ability of damselfish to distinguish between dangerous and harmless sea snakes. Sci. Rep. 10, 1377 (2020). 10.1038/s41598-020-58258-2 
36. Sato, H., Sakai, Y. \& Kuwamura, T. Non-mimic color variant of the false cleanerfish Aspidontus taeniatus found in Okinawa, Japan. Galaxea, J. Coral Reef Stud. 22, 1-2 (2020) 10.3755/galaxea.22.1_1

37. Ormond, R. F. G. Aggressive mimicry and other interspecific feeding associations among Red Sea coral reef predators. J. Zool. 191, 247-262 (1980). 10.1111/j.1469-7998.1980.tb01458.x

38. Foster, S. A. Group foraging by a coral reef fish: a mechanism for gaining access to defended resources. Anim. Behav. 33, 782-792 (1985). 10.1016/S0003-3472(85)80011-7

39. Yoshino, T. \& Nishijima, S. A list of fishes found around Sesoko Island, Okinawa. Sesoko Mar. Sci. Lab. Tech. Rep. 8, 19-87 (1981).

40. Manica, A. Alternative strategies for a father with a small brood: mate, cannibalise or care. Behav. Ecol. Sociobiol. 51, 319-323 (2002). 10.1007/s00265-001-0444-0

41. R Development Core Team. R: A language and environment for statistical computing: https://www.rproject.org, 2020

\section{Table}

Table 1. List of the target species whose nests false cleanerfish, Aspidontus taeniatus raided, the number of raiding bouts, nest type, nest coloniality, and months of observation. 


\begin{tabular}{|c|c|c|c|c|}
\hline Species name & $\begin{array}{l}\text { Number of } \\
\text { bouts }\end{array}$ & $\begin{array}{l}\text { Nest } \\
\text { type* }\end{array}$ & $\begin{array}{l}\text { Nest } \\
\text { coloniality }\end{array}$ & Months of observation \\
\hline \multicolumn{5}{|l|}{ Pomacentridae } \\
\hline Abudefduf sexfasciatus & 41 & Open & Yes & Apr., May, June, July, Aug. \\
\hline $\begin{array}{l}\text { Pomacentrus } \\
\text { amboinensis }\end{array}$ & 20 & Closed & No & Apr., May, June, July, Sept. \\
\hline $\begin{array}{l}\text { Amblyglyphidodon } \\
\text { curacao }\end{array}$ & 18 & Open & No & May, June, July \\
\hline Stegastes obreptus & 8 & Closed & No & Apr., May, July \\
\hline Chrysiptera cyanea & 8 & Closed & No & June, July \\
\hline $\begin{array}{l}\text { Plectroglyphidodon } \\
\text { lacrymatus }\end{array}$ & 8 & Closed & No & $\begin{array}{l}\text { Apr., May, June, Aug., } \\
\text { Sept. Oct. }\end{array}$ \\
\hline Dascyllus trimaculatus & 7 & Open & No & July, Sept. \\
\hline Pomacentrus chrysurus & 5 & Closed & No & June, July \\
\hline Stegastes nigricans & 3 & Closed & Yes & July, Aug. \\
\hline Stegastes fasciolatus & 3 & Closed & No & June, July \\
\hline Chrysiptera rex & 3 & Closed & No & June \\
\hline Plectroglyphidodon dickii & 2 & Open & No & Apr. \\
\hline Chromis margaritifer & 1 & Closed & No & June \\
\hline \multicolumn{5}{|l|}{ Balistidae } \\
\hline Sufflamen chrysopterum & 1 & Open & No & Aug. \\
\hline
\end{tabular}

*Open, eggs are attached on a visible surface: Closed, eggs are deposited in an invisible deep place.

\section{Figures}




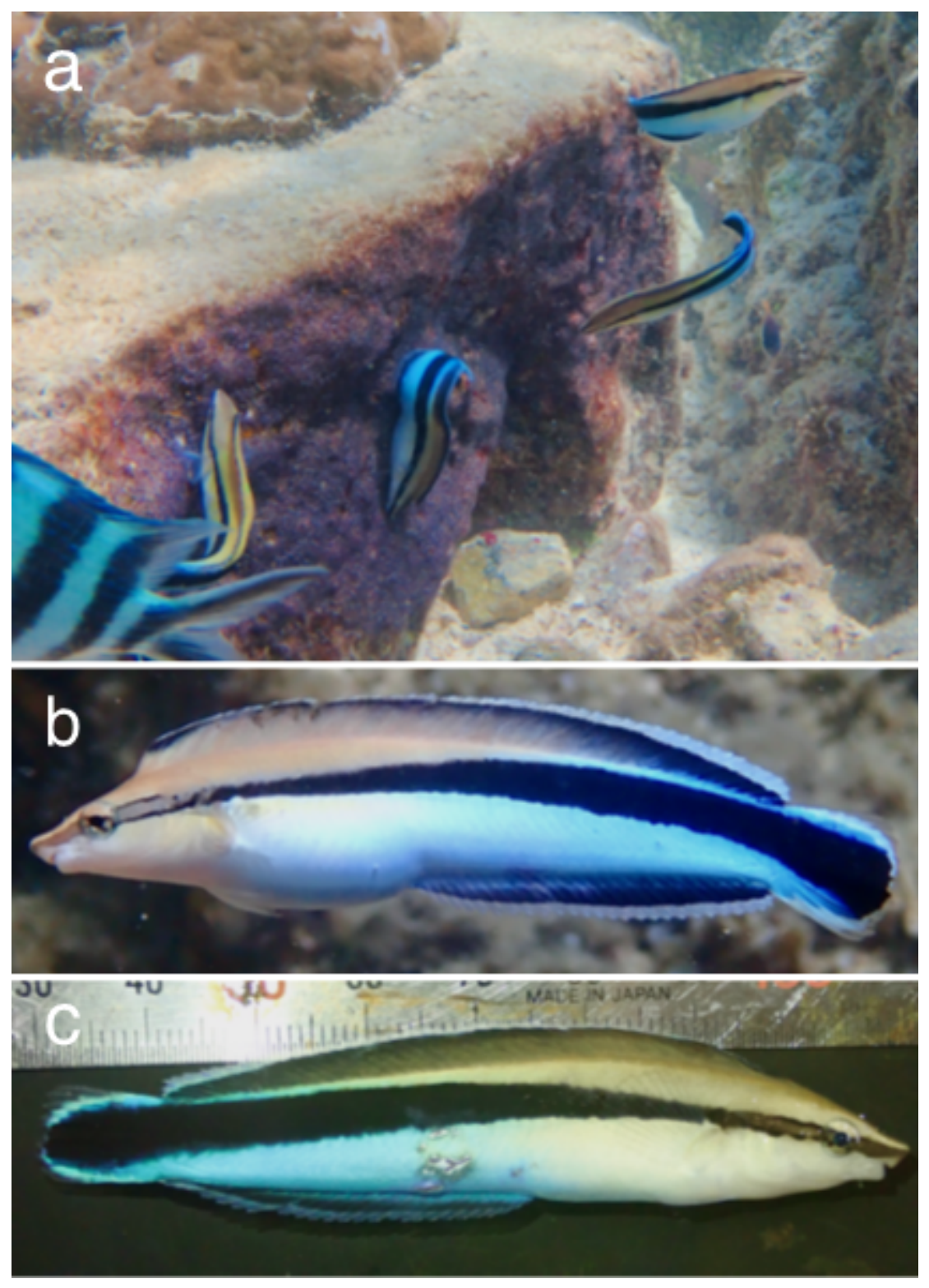

\section{Figure 1}

Photographs of egg-eating behavior in a group and its benefits and costs in the false cleanerfish, Aspidontus taeniatus. A. taeniatus feeding on demersal eggs (purple) of the scissors-tail sergeant Abudefduf sexfasciatus (a). A swollen abdomen from eating a sufficient amount of eggs (b), and injuries on the side of the body (c). All these photographs were taken on a reef of Sesoko Island by Hajime Sato. 


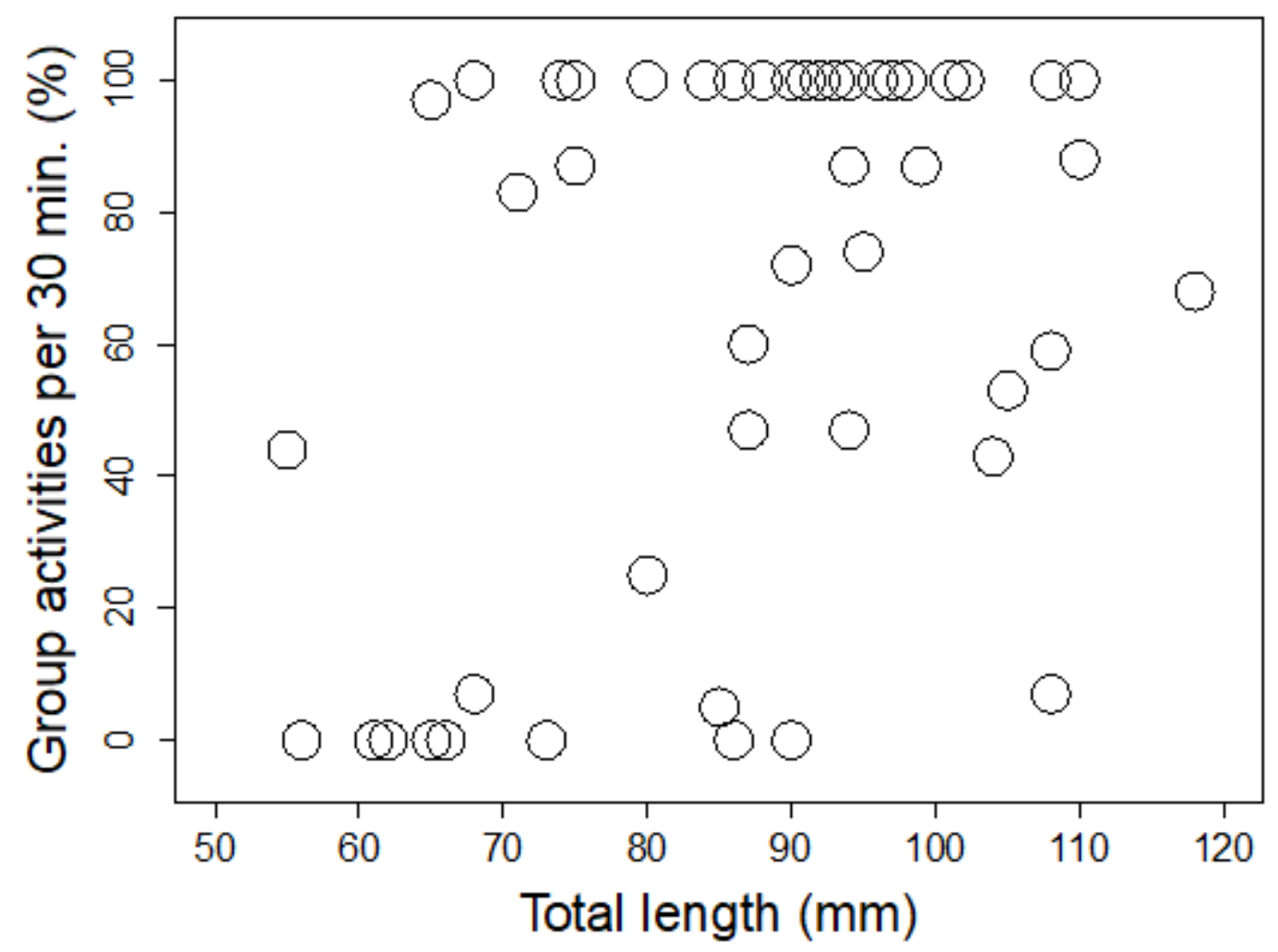

Figure 2

Relationship between group activity and total length in the false cleanerfish, Aspidontus taeniatus.

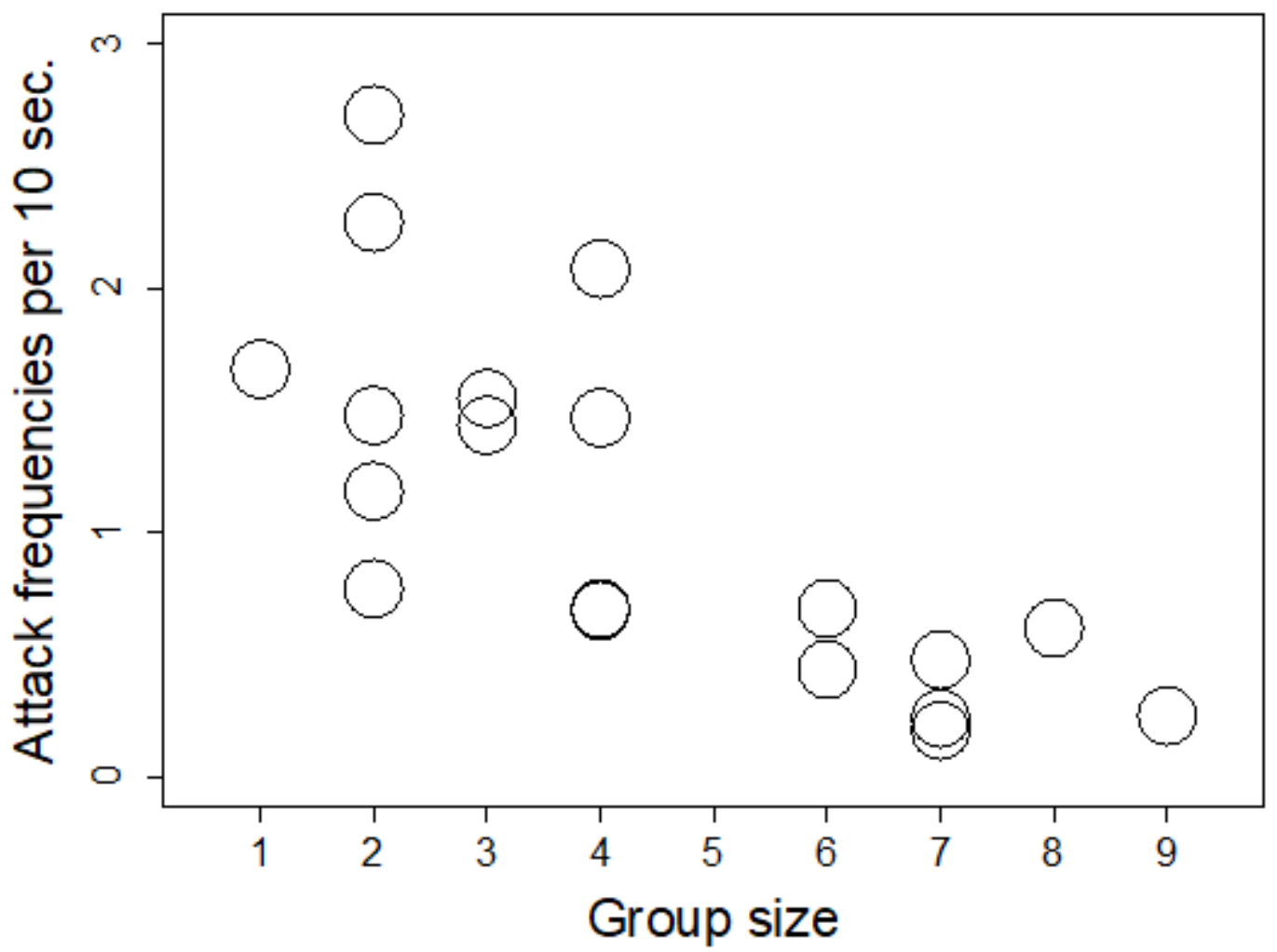


Figure 3

Relationship between attack frequencies per 10 seconds from the scissors-tail sergeant, Abudefduf sexfasciatus, and group size of the false cleanerfish, Aspidontus taeniatus. When there is overplotting, the sample size is shown in the circle.

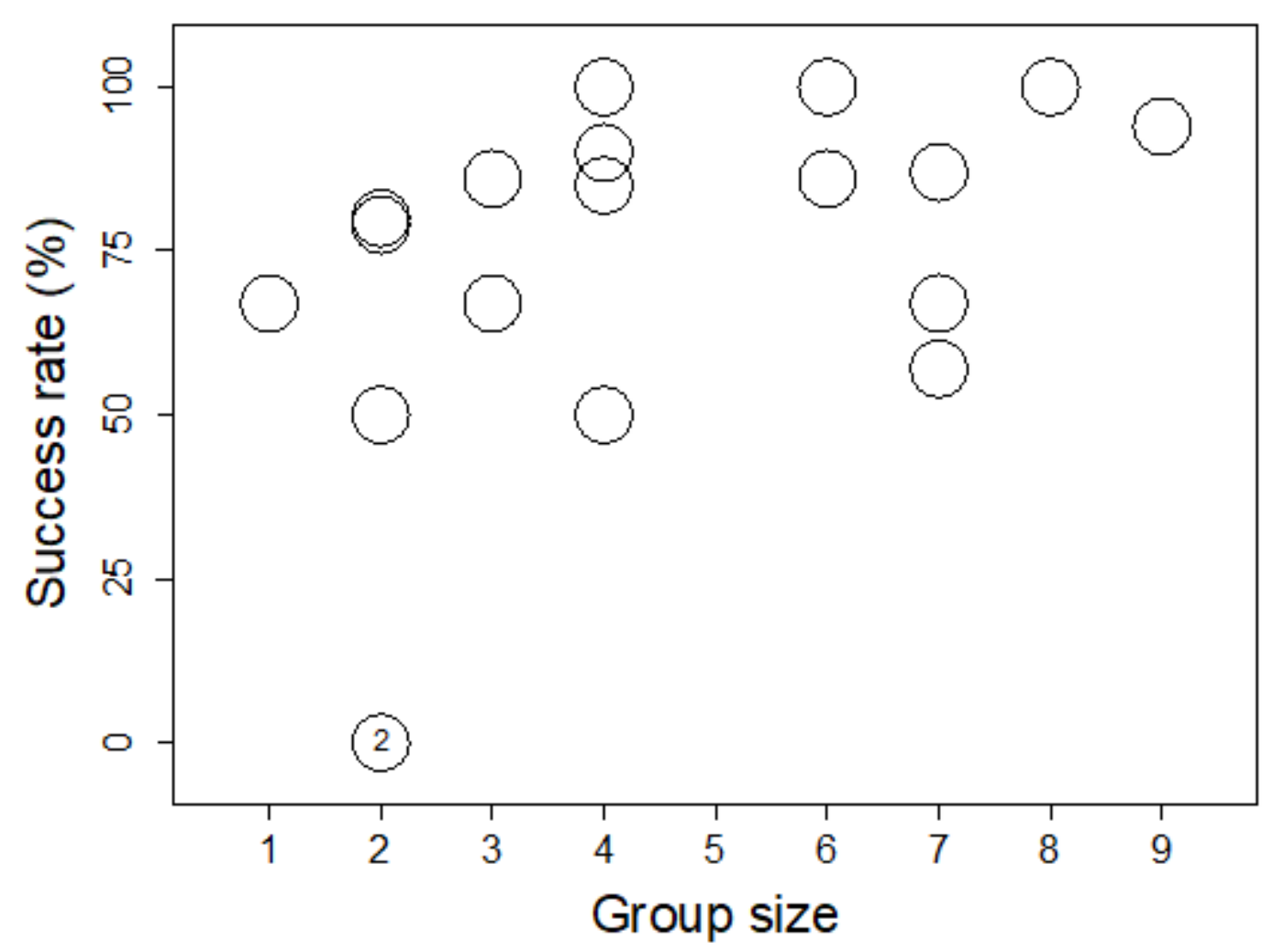

Figure 4

Relationship between the success rate of invasion towards the nest of the scissors-tail sergeant, Abudefduf sexfasciatu, and group size of the false cleanerfish, Aspidontus taeniatus.

\section{Supplementary Files}

This is a list of supplementary files associated with this preprint. Click to download.

- VideoS1.mov 